\title{
Equilibrium contrast CMR for the detection of amyloidosis in mice
}

\author{
Adrienne E Campbell ${ }^{1 *}$, Anthony N Price ${ }^{2}$, Stephan Ellmerich ${ }^{3}$, Paul Simons ${ }^{3}$, Raya Al-Shawi ${ }^{3}$, Philip N Hawkins ${ }^{3}$, \\ Roger J Ordidge ${ }^{4}$, Mark B Pepys ${ }^{3}$, James C Moon ${ }^{5}$, Mark F Lythgoe ${ }^{1}$
}

From 2011 SCMR/Euro CMR Joint Scientific Sessions

Nice, France. 3-6 February 2011

\section{Objective}

In this study, we optimise equilibrium contrast CMR (EQ-CMR) protocols in mice and apply EQ-CMR to detect AA amyloidosis in the heart and liver of mice with inducible transgenic overexpression of serum amyloid A protein.

\section{Background}

Systematic amyloidosis is a severe, diagnostically challenging, disorder characterised by the extracellular deposition of insoluble abnormal protein fibrils [1]. Recently, Flett et al [2] showed that the volume of distribution of gadolinium (Gd) contrast agents, calculated by EQ-CMR, can be used to measure fibrosis. This technique uses the extracellular nature of $\mathrm{Gd}$ to relate the volume of distribution of the agent $\left(V_{d}\right)$ to extracellular pathology.

\section{Methods}

A bolus followed by steady infusion of Magnevist was used to generate a blood - tissue equilibrium of [Gd]. The optimal dose and timing protocol, determined empirically, is displayed in Figure 1. An ECG-gated Look-Locker technique [3] was used to measure the $T_{1}$ and the $V_{d}$ can be calculated: $V_{d}=\Delta R_{1, \text { tissue }} / \Delta R_{1 \text {,blood }}$

Nine control and 11 amyloidotic mice [4] (confirmed by histology to have major amyloid deposits in the liver and minor deposits in the heart) were imaged using a standard cine stack and EQ-CMR. A mid-ventricle short-axis slice through the heart, which included a section of liver was used. The hematocrit (Hct) was measured using a blood sample from the tail vein.

${ }^{1}$ Centre for Advanced Biomedical Imaging, University College London, London, UK

Full list of author information is available at the end of the article

\section{Results}

Analysis of cardiac functional parameters calculated from cine images showed no significant difference between the groups. Figure 2 presents box-and-whisker plots comparing $\mathrm{V}_{\mathrm{d}}$ between groups for the (a) myocardium and (b) liver. The amyloidotic group shows a significantly increased $V_{d}$ of Gd compared to the control group in both organs. The $\mathrm{V}_{\mathrm{d}}$ of the control group was $15.4 \% \pm 0.2 \%$ (myocardium) and $15.4 \pm 0.3 \%$ (liver) and of the amyloidotic group $19.8 \pm 0.4 \%$ (myocardium) and $23.6 \pm 0.4 \%$ (liver) (mean \pm s.e.m).

\section{Conclusion}

An EQ-CMR procedure has been optimised in the mouse. The results of this study show that EQ-CMR techniques can detect minor amyloid deposits with good sensitivity. This approach has the potential to become a sensitive diagnostic tool with considerable utility in serial quantitative monitoring of response to novel therapy aimed at elimination of amyloid deposits $[5,6]$.

\footnotetext{
Author details

Published: 2 February 2011

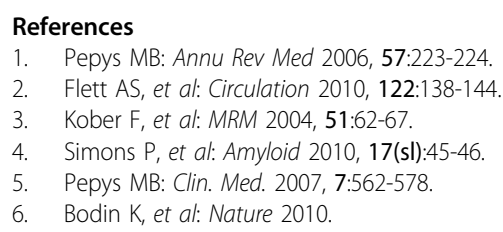

${ }^{1}$ Centre for Advanced Biomedical Imaging, University College London, London, UK. ${ }^{2}$ Robert Steiner MRI Unit, Imperial College London, London, UK. ${ }^{3}$ Centre for Amyloidosis and Acute Phase Proteins, Division of Medicine, University College London, London, UK. ${ }^{4}$ Department of Medical Physics and Biomedical Engineering, University College London, London, UK. ${ }^{5}$ Heart Hospital and Division of Medicine, University College London, London, UK.

(C) 2011 Campbell et al; licensee BioMed Central Ltd. This is an open access article distributed under the terms of the Creative Commons Attribution License (http://creativecommons.org/licenses/by/2.0), which permits unrestricted use, distribution, and reproduction in any medium, provided the original work is properly cited. 


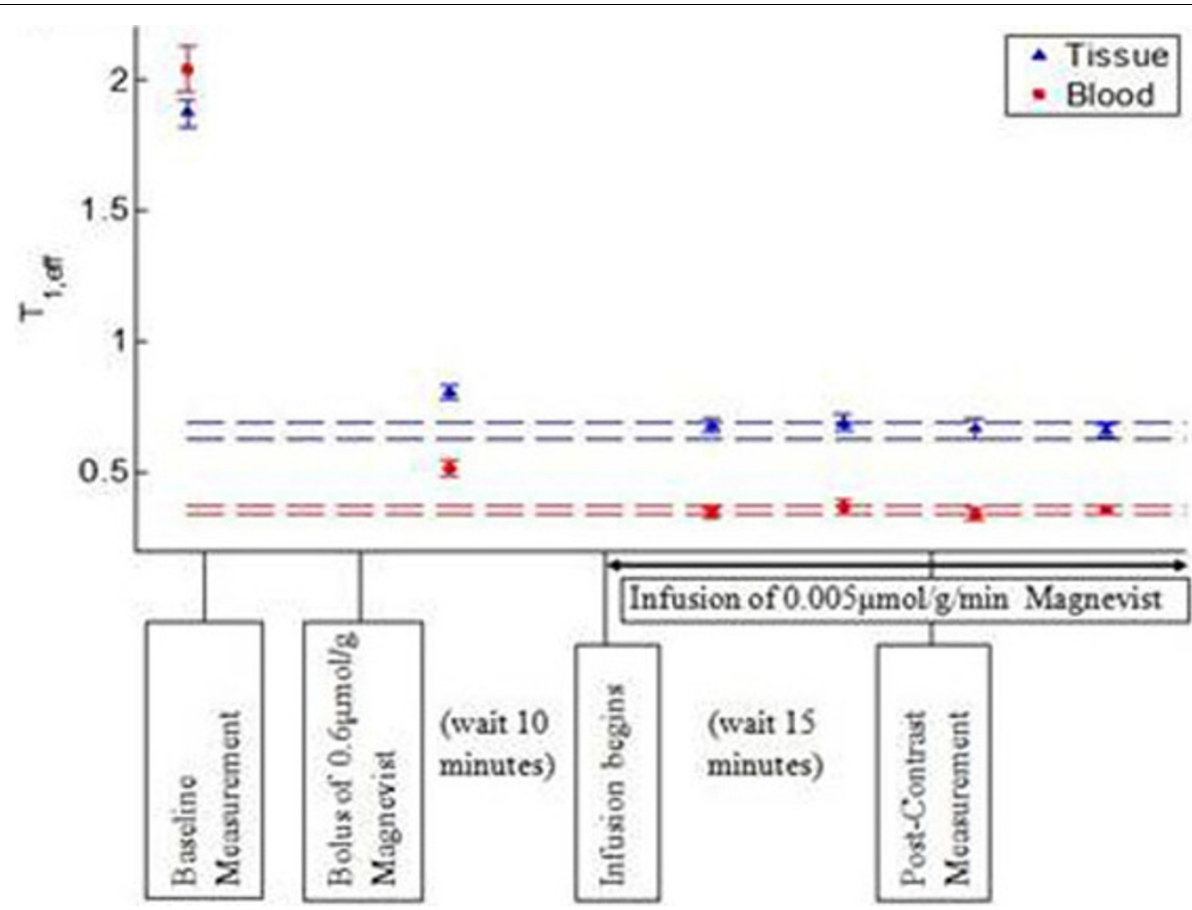

Figure $1 \mathrm{~T} 1$, eff plotted to demonstrate the optimized equilibrium protocol in mice. Dotted lines represent values within $5 \%$ of final $\mathrm{T} 1$ measurement (defined as equilibrium).
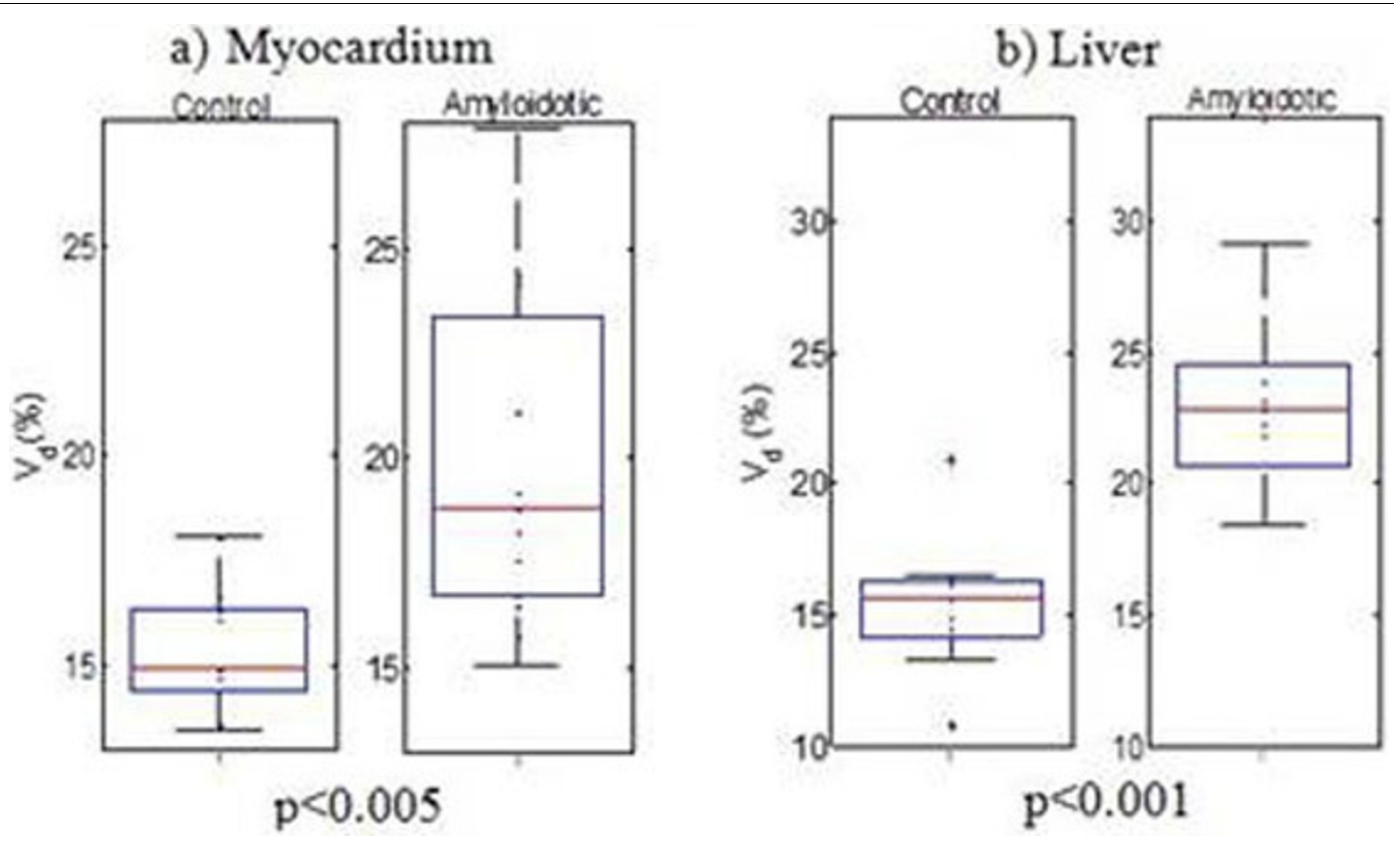

Figure 2 Comparison of $V_{d}$ between groups. 